\title{
Something borrowed, something blue: A gift for the bride with everything, including an ectopic parathyroid adenoma
}

\author{
Jules Lin, MD
}

\footnotetext{
From the Department of Surgery, Section of Thoracic Surgery, University of Michigan Medical Center, Ann Arbor, Mich.

Disclosures: Author has nothing to disclose with regard to commercial support.

Received for publication Oct 10, 2015; accepted for publication Oct 18, 2015; available ahead of print Nov 21, 2015.

Address for reprints: Jules Lin, MD, Department of Surgery, Section of Thoracic Surgery, 1500 E Medical Center

Dr, 2120TC/5344, Ann Arbor, MI 48109-5344 (E-mail: juleslin@umich.edu).

J Thorac Cardiovasc Surg 2016;151:e35-6

$0022-5223 / \$ 36.00$

Copyright (C) 2016 by The American Association for Thoracic Surgery

http://dx.doi.org/10.1016/j.jtcvs.2015.10.046
}

Something old, something new, something borrowed, something blue is a bit of an old English rhyme describing tokens of good luck for a bride. In this case report, Madou and colleagues $^{1}$ marry old and new using a combination of a transpericardial resection of an ectopic parathyroid and intraoperative parathyroid hormone (PTH) monitoring. With a history of a failed parathyroidectomy, transcervical thymectomy, and mantle radiation, mediastinoscopy was not believed to be a good option for this patient. In addition, the adenoma was posteromedial to the aorta, making a thoracoscopic approach difficult.

Parathyroidectomy is curative in $98 \%$ of cases of primary hyperparathyroidism. Persistent hyperparathyroidism can be due to an ectopic or supernumerary gland. Ectopic mediastinal glands are found in $6 \%$ to $16 \%$ of patients with primary hyperparathyroidism and $29 \%$ to $45 \%$ of patients failing neck exploration. Mediastinal parathyroid glands result from abnormal migration of the parathyroids during development, with $24 \%$ to $38 \%$ in the thymus and $6 \%$ to $26 \%$ in the middle mediastinum. ${ }^{2,3}$ Clinical and laboratory findings can be more severe with ectopic adenoma.

\section{SOMETHING OLD}

Whereas the majority of mediastinal parathyroid adenomas can be resected with a transcervical thymectomy, $2 \%$ require additional mediastinal dissection - traditionally performed by sternotomy or thoracotomy-and detailed knowledge of embryologic variations. In this case, a mediastinal parathyroid adenoma was resected using a transpericardial approach. With the evolution of minimally invasive techniques, open approaches have become less common. This case highlights the importance of keeping these open techniques in our armamentarium. Donor procurements provide an excellent opportunity to teach resident physicians this anatomy by incising the posterior pericardium between the aorta and superior vena cava, providing exposure of the distal trachea and carina.



See Article page e33.

\section{SOMETHING NEW}

Although $95 \%$ of experienced endocrine surgeons can locate a cervical adenoma without imaging studies, localization is important in determining the approach and minimizing dissection for mediastinal adenomas, with a $33 \%$ to $40 \%$ failure rate without preoperative imaging. ${ }^{4}$ Ectopic mediastinal parathyroid glands need to be distinguished from lymph nodes or thymic tissue. It is also important to note that $64 \%$ of missing glands were found in normal locations in 1 study $^{5}$ suggesting these glands were missed by less-experienced surgeons. In this case report, computed tomography (CT) showed a $9 \times 4 \mathrm{~mm}$ nodule in the posterior subaortic space. Neck ultrasound, sestamibi-single proton emission CT, and 4-dimensional CT were negative. Technetium-sestamibi scans have a sensitivity of $80 \%$ to $90 \%$. Sensitivity can be increased with double-phase scintigraphy obtaining early and late images to avoid rapid sestamibi washout and by combining single photon emission computed tomography with CT, increasing sensitivity to $96 \%$.

Newer modalities like 4-dimensional CT, positron emission tomography/CT, and positron emission tomography/ magnetic resonance imaging can be useful when other tests fail to localize the adenoma. The success of re-exploration depends on accurate localization and the number of parathyroid adenomas, and patients should undergo at least 2 noninvasive imaging studies. Wei and colleagues ${ }^{6}$ found a $100 \%$ cure rate 
with 2 concordant studies but only $60 \%$ with 1 positive study. When localizing studies are negative, selective venous sampling can confirm a mediastinal source of PTH with a sensitivity of $95 \%$. Fine needle aspiration with endobronchial ultrasound and measurement of PTH could also be used.

Due to advances in preoperative localization, minimally invasive parathyroidectomy avoiding 4-gland exploration is possible along with mediastinoscopy, thoracoscopy, and robotic approaches that minimize dissection for mediastinal adenomas and decrease complications and length of stay. ${ }^{6}$ Whereas mediastinoscopy can be performed safely by experienced surgeons after induction chemoradiation for lung cancer, complications, including azygous and recurrent nerve injuries, are more common. ${ }^{7}$ Experience with mediastinoscopy in complex cases is also decreasing among thoracic trainees with increasing use of endobronchial ultrasound, and the open approach taken here is reasonable with a history of mantle radiation.

Intraoperative sestamibi scanning can be used for adenomas that are difficult to locate, although myocardial uptake increases the background level. Intraoperative PTH monitoring is also highlighted in this report as having reduced the failure rate of surgery by confirming a decrease in PTH of at least $50 \%$ after resection. Persistently elevated levels suggest that the adenoma was not resected or that there are additional glands. Frozen section is not necessary but can be used to confirm parathyroid tissue when PTH levels fail to decrease. The authors also aspirated the resected gland to confirm the presence of PTH.

\section{SOMETHING BORROWED}

Although uncommon, middle mediastinal ectopic parathyroid adenomas can be challenging for surgeons. With advances in imaging, minimally invasive approaches are possible. These approaches avoid extensive dissection, and some have argued that a negative neck exploration is not needed before proceeding directly to mediastinal resection. ${ }^{8}$ The authors present an interesting and instructive case of a patient with an adenoma difficult to approach by video-assisted thoracoscopic surgery or mediastinoscopy. Using something old and something new, Madou and colleagues ${ }^{1}$ offer readers something to borrow, combining an open transpericardial approach with intraoperative PTH monitoring. Finally, to end with something blue because I hail from the University of Michigan: Go blue!

\section{References}

1. Madou ID, Callender GG, Kim AW. Something old, something new: marrying two approaches to resect an ectopic parathyroid adenoma. J Thorac Cardiovasc Surg. 2016;151:e33-4.

2. Jaskowiak N, Norton JA, Alexander HR, Doppman JL, Shawker T, Skarulis M, et al. A prospective trial evaluating a standard approach to reoperation for missed parathyroid adenoma. Ann Surg. 1996;224:308-20; discussion 20-1.

3. Shen W, Duren M, Morita E, Higgins C, Duh QY, Siperstein AE, et al. Reoperation for persistent or recurrent primary hyperparathyroidism. Arch Surg. 1996;131: 861-7; discussion 7-9.

4. Wang C, Gaz RD, Moncure AC. Mediastinal parathyroid exploration: a clinical and pathologic study of 47 cases. World J Surg. 1986;10:687-95.

5. Yen TW, Wang TS, Doffek KM, Krzywda EA, Wilson SD. Reoperative parathyroidectomy: an algorithm for imaging and monitoring of intraoperative parathyroid hormone levels that results in a successful focused approach. Surgery. 2008;144:611-9; discussion 9-21.

6. Wei B, Inabnet W, Lee JA, Sonett JR. Optimizing the minimally invasive approach to mediastinal parathyroid adenomas. Ann Thorac Surg. 2011;92:1012-7.

7. Louie BE, Kapur S, Farivar AS, Youssef SJ, Gorden J, Aye RW, et al. Safety and utility of mediastinoscopy in non-small cell lung cancer in a complex mediastinum. Ann Thorac Surg. 2011;92:278-82; discussion 82-3.

8. Randone B, Costi R, Scatton O, Fulla Y, Bertagna X, Soubrane O, et al. Thoracoscopic removal of mediastinal parathyroid glands: a critical appraisal of an emerging technique. Ann Surg. 2010;251:717-21. 